\title{
Trickle-Up Political Socialization The Causal Effect on Turnout of Parenting a Newly Enfranchised Voter
} Dahlgaard, Jens Olav

Document Version

Accepted author manuscript

Published in:

American Political Science Review

DOI:

$10.1017 / \mathrm{S} 0003055418000059$

Publication date:

2018

License

Unspecified

Citation for published version (APA):

Dahlgaard, J. O. (2018). Trickle-Up Political Socialization: The Causal Effect on Turnout of Parenting a Newly Enfranchised Voter. American Political Science Review, 112(3), 698-705.

https://doi.org/10.1017/S0003055418000059

Link to publication in CBS Research Portal

\section{General rights}

Copyright and moral rights for the publications made accessible in the public portal are retained by the authors and/or other copyright owners and it is a condition of accessing publications that users recognise and abide by the legal requirements associated with these rights.

Take down policy

If you believe that this document breaches copyright please contact us (research.lib@cbs.dk) providing details, and we will remove access to the work immediately and investigate your claim. 


\title{
Trickle-Up Political Socialization: The Causal Effect on Turnout of Parenting a Newly Enfranchised Voter
}

\section{Jens Olav Dahlgaard}

\author{
Journal article (Accepted manuscript*)
}

\section{Please cite this article as:}

Dahlgaard, J. 0. (2018). Trickle-Up Political Socialization: The Causal Effect on Turnout of Parenting a Newly Enfranchised Voter. American Political Science Review, 112(2), 698-705. 001: 10.1017/S0003055418000059

\section{This article has been published in a revised form in American Political Science Review http://dx.doi.org/10.1017/S0003055418000059.}

This version is free to view and download for private research and study only. Not for re-distribution, re-sale or use in derivative works. (0) Cambridge University Press

* This version of the article has been accepted for publication and undergone full peer review but has not been through the copyediting, typesetting, pagination and proofreading process, which may lead to differences between this version and the publisher's final version AKA Version of Record.

Uploaded to CBS Research Portal: February २०19 


\title{
Trickle-up Political Socialization: the Causal Effect on Turnout of Parenting a Newly Enfranchised Voter
}

\author{
Jens Olav Dahlgaard* \\ Department of Business and Politics \\ Copenhagen Business School
}

January 7, 2018

\begin{abstract}
PREPRINT OF
DAHLGAARD, JENS OLAV. Trickle-Up Political Socialization: The Causal Effect on Turnout of Parenting a Newly Enfranchised Voter. American Political Science Review, 2018, 1-8.
\end{abstract}

\begin{abstract}
Scholars have argued that children affect their parents' political behavior, including turnout, through so-called trickle-up socialization. However, there is only limited causal evidence for this claim. Using a regression discontinuity design on a rich dataset, with validated turnout from subsets of Danish municipalities in four elections, I causally identify the effect of parenting a recently enfranchised voter. I consistently find that parents are more likely to vote when their child enters the electorate. On average across all four elections, I estimate that parents become 2.8 percentage points more likely to vote. In a context where the average turnout rate for parents is around $75 \%$, this is a considerable effect. The effect is driven by parents whose children still live with them while there is no discernible effect for parents whose child has left home. The results are robust to a range of alternative specifications and placebo tests.

KEYWORDS: Political socialization, voter turnout, causal inference.
\end{abstract}

*jod.dbp@cbs.dk. Mailing address: Steen Blichers Vej 22, DK-2000 Frederiksberg, Denmark

This research has primarily been funded by the Danish Council for Independent Research (grant no. 12124983). The project has also received funding from the Danish Youth Council, The Ministry of Children, Equality, Integration, \& Social Affairs, and the Danish Parliament. I am grateful to Klaus Levinsen, Bolette Danckert, Jonas Hedegaard Hansen, Yosef Bhatti, Kasper Møller Hansen, Christian Rostbøll, Peter Thisted Dinesen, Martin Vinæs Larsen, Søren Serritzlew, Signe Hald Andersen, Lindsay Dolan, Jacob Gerner Hariri, David Dreyer Lassen, three anonymous reviewers, and discussants and panel participants in the 2015 yearly meeting of Midwestern Political Science Association, the 2015 yearly meeting of European Political Science Association, and the 2016 Youth Political Participation Conference at McGill for thoughts and comments on previous versions of this paper. A special thank is dedicated to Alex Coppock and Don Green both of whom have provided help beyond any reasonable expectation. All remaining errors are my responsibility. I was a PhD candidate at the Department of Political Science at the Unversity of Copenhagen when the 


\section{Introduction}

A long line of research on political socialization concerns the intergenerational transmission of political attitudes and behavior through which children come to resemble their parents, with an emphasis on parentchild links, such as social learning and social milieu (Jennings and Niemi 1968, Tedin 1974, Jennings and Niemi 1981, Sears and Funk 1999, Plutzer 2002, Jennings, Stoker and Bowers 2009). However, scholars have also argued that adolescents have the potential to affect the attitudes and behaviors of their parents through the so-called trickle-up effect (Jennings and Niemi 1981, Simon and Merrill 1998, McDevitt and Chaffee 2000, 2002, Linimon and Joslyn 2002). In this paper, I ask the specific question: does a parent become more likely to vote when one of his or her children enters the electorate?

I contribute by using a regression discontinuity (RD) design in a rich dataset of validated turnout, demographic information, and a parent-child link for Danish voters, to identify how parents become more likely to vote as their child enters the electorate. I rely on validated turnout from Danish voters in four elections. For each election, I find that parents of recently eligible children are more likely to vote compared to parents of children who are just ineligible. The precision weighted average of the effects is 2.8 percentage points, which implies that about one out of nine parents becomes mobilized when his or her child comes of age. The effect is only present for parents who live with their children.

\section{The effects of child characteristics}

Although the classic literature primarily focuses on political socialization from parent to child, it acknowledges that children could also affect their parents through so-called reverse socialization (Hyman 1959, 72; Jennings and Niemi 1981, 82,101). This perspective has received recent attention focusing on more complex social patterns explaining the resemblance between parents and children, including the idea that children's characteristics, attitudes, and behavior can causally affect parents (Jennings, Stoker and Bowers 2009, Washington 2008, Glynn and Sen 2015, Urbatsch 2014, 9-11). One strand of the literature has emphasized the impact that adolescents have on their parents as they come of age through trickle-up political socialization (Simon and Merrill 1998, McDevitt and Chaffee 2000, 2002, Linimon and Joslyn 2002, Wong and Tseng 2008). My main contribution is to use a rich administrative dataset to provide new and causally identified evidence to show that trickle-up socialization in families can potentially explain a substantial part of the relationship between parents' and children's attitudes and behaviors.

manuscript was conceived and gratefully acknowledge the general support during this time. All replication data and code will be made available for replication except when explicitly exempted. 
Two mechanisms could explain why parents would become more likely to vote when one of their children enters the electorate. First, parents might have already inculcated a norm, which makes them likely, but not guaranteed, to vote, and as their child enters the electorate, they want to convey that norm to their children (Gidengil, Wass and Valaste 2016). Another likely mechanism, which I will call trickle-up socialization, is that a newly enfranchised voter becomes engaged in the election. Parents could either be persuaded to vote or, as McDevitt and Chaffee $(2002,292)$ suggest, parents could adjust their behavior because they take on the role of maintaining family stability, which is enforced when parents and children behave in accordance with each other. In the discussion, I offer some insights from heterogeneous effects suggesting that both potential mechanisms play a role.

\section{Children's date of birth as an identification strategy}

How do we identify the effect children have on their parents? Comparing voters with and without children would be biased, since people select in to parenthood. Likewise, correlating the behavior of parents and children would be problematic, since that correlation is also driven by traditional socialization and exposure to common surroundings (Cho and Rudolph 2008, Jennings, Stoker and Bowers 2009). A trivial, yet important, observation is that eligible children may vote, whereas ineligible children will not vote. We can use this to identify how parents respond to their children coming of age. In general, comparing parents with young and old children would also be biased, since voters may have unobserved preferences for when to have children. Instead comparing parents over the cutoff of their children's eligibility can give causal identification, at least in a local area around the age-threshold. It is a perfect setting for an RD design.

In the $\mathrm{RD}$ design, a forcing variable sorts cases into either a treatment or a control condition separated by a threshold (Imbens and Lemieux 2008). In my application, the treatment condition is having a child who is eligible to vote, the control condition is having a child who is not, and the forcing variable is the age of the child in days. If parents of eligible voters show a higher degree of turnout, it means that their eligible child somehow affects them. Previous research has used a similar design to estimate the effect of past eligibility on future turnout and party identification (Meredith 2009, Dinas 2014, Coppock and Green 2015, Bhatti, Hansen and Wass 2016, Nyhan, Skovron and Titiunik 2017). However, to the best of my knowledge, this paper is the first to use it as a source of exogenous variation for family members. This is possible with the rich Danish administrative data. 


\section{Context and data}

The study relies on data from two rounds of the Danish Municipal Elections held on November 17, 2009, and November 19, 2013; the European Parliament Elections held on May 25, 2014; and the National Election held on June 18, 2015. The municipality elections take place simultaneously in all 98 Danish municipalities every fourth year. The elections had an overall turnout of 65.8 and 71.9 percent in 2009 and 2013, respectively. The 2014 European Parliament Elections are nationwide and held every five years. Turnout in 2014 was 56.3 percent. The Prime Minister calls the National Election no more than four years after the previous election. Turnout in 2015 was 85.8 percent.

All Danes have a unique civil registration number, which identifies them in public registers. Registration in administrative data is automatic and required for everyone with permanent residence in Denmark and for this study, I have access to de-identified, full population data for all four elections. The Danish administrative data are incredibly rich and contain, among many other things, individual birthdates, ethnicity, sex, education, and income for the entire population. Consequently, I know any person's exact age in days on election day. The data also include the de-identified civil registration numbers of an individual's parents, which allows me to easily match parents to their children and deduce if the parents' children are old enough to vote on election day. I also know voters' addresses, which allow me to estimate the effects conditioned on cohabitation.

One thing not routinely stored in the public records is turnout. However, in 2009, validated turnout from the official voting records for 2.3 million of 4.4 million voters was linked to the administrative data; in 2013 it was done for 98.9 percent of all Danish voters; in 2014 it was again done for roughly 2.3 million voters; and in 2015, around 3.1 million voters were linked. The number of included voters varies over elections because, contrary to the rest of the data used in the analyses, the collection of turnout data relied on opt-in participation by the municipalities. In 2009, 2014 and 2015, only some municipalities chose to participate, whereas all did so in 2013. In all four elections, the municipalities committed to partipate several months prior to the election.

The fact that varying subsets of municipalities participates across the elections is a challenge. We try to estimate the same parameter across elections, but when the subset changes, so does the parameter that we estimate. Within the participating voting districts in each election, I have data on all voters, allowing me to causally identify effects in the subset of participating municipalities. For 2013, that gives us an effect estimate for the entire country. For all other elections, we get an effect estimate for the municipalities that

opted to participate. If that varies, it could be because the effect is different in another election, or because it is a new set of voters being treated in the election, or because voters respond differently in the excluded 
municipalities.

Although I only have turnout for some municipalities, I still argue that my study has advantages over other studies that have relied on primarily American voter lists. The fact that I have complete voter lists for an entire country in even one election is rare, and the parent-child link is an innovation over previous datasets. For instance, the previous studies using American voter lists rely on state-wide voter files for between one and 42 states, plus the District of Columbia (Meredith 2009, Coppock and Green 2015, Holbein and Hillygus 2016, Nyhan, Skovron and Titiunik 2017). Still, I report two sets of results for my main finding. First, I use all the municipalities with data in each year. For this set, the parameter changes from year to year, which we need to take into account when we take precision weighted averages of the results. Second, I present results for only the 32 municipalities that report turnout in all four years. For this set, the target population is fixed over the elections. The results are very similar. Each yearly estimate is well within sampling variability, and the precision weighted averages are 0.09 percentage points apart.

\section{The causal effect of child eligibility on parent turnout}

In a classic motivation for the RD design, the forcing variable is continuous and the design relies on the assumptions that units are unable to sort exactly around the cutoff; that the potential outcomes are continuous in the cutoff; and that the forcing variable has positive density around the cutoff (Hahn, Todd and Van der Klaauw 2001, Lee and Lemieuxa 2010, Cattaneo, Titiunik and Vazquez-Bare 2016). It seems reasonable that parents cannot and do not decide when to have children based on an election 18 years later. With respect to the other assumptions, we have in this case a discrete forcing variable, the age of the child in days, in which case a polynomial fit implies extrapolation of one day, as there are no data on the exact cutoff. Lee and Card (2008, 657-660) recommend using a regression model where the outcome of interest is expressed as an indicator variable for being in the treatment condition plus some function of the forcing variable. I follow their recommendation and as a heuristic, we can think of a regression of the form:

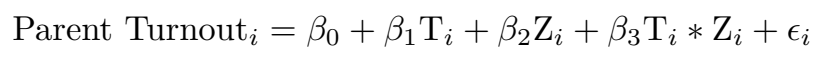

where Parent Turnout ${ }_{i}$ is the outcome of interest, $T$ is an indicator equal to one when the children are eligible to vote, $Z$ is the children's age in days, which I set to zero for parents whose child became eligible on election day, and $\epsilon$ is the error term. The main parameter of interest, $\beta_{1}$, gives us the jump of parents' turnout in the cutoff, and we can interpret it as the causal estimate of parenting a recently eligible child. The interaction between the forcing variable and the indicator variable for child eligibility means that I allow 
the forcing variable to have different slopes on either side of the threshold.

We use the rdrobust-package for $\mathrm{R}$ to estimate the effect in the cutoff (Calonico et al. 2017). The software includes an algorithm for choosing the estimation windows, that is the number of days around the threshold I include observations for, and by default assigns triangular weights to the observations as a function of the distance to the cutoff. The software returns both a conventional and a robust estimate and standard errors, and I report both. ${ }^{1}$ I use the default options in the package. See Calonico et al. (2017) for details. The model is estimated individually for each of the four elections in question and I also take a precision weighted average of the four estimates (Gerber and Green 2012, 362).

Some parents have two or more children who enter the electorate within the estimation window. I omit the parents if the children enter the electorate on separate sides of the cutoff. I keep the parents who have more than one child entering the electorate within the estimation window on the same side of the cutoff (primarily, the parents of twins), but I make sure to only count them once. In the few cases where fathers have more than one child with different mothers on the same side of the cutoff, I randomly choose which of the days to cluster the father with.

\footnotetext{
${ }^{1}$ Ideally, I would cluster standard errors by the child. However, due to privacy concerns, I can only make data clustered by day publicly available. In the supporting information, I show that the standard errors are marginally larger when I cluster by child.
} 


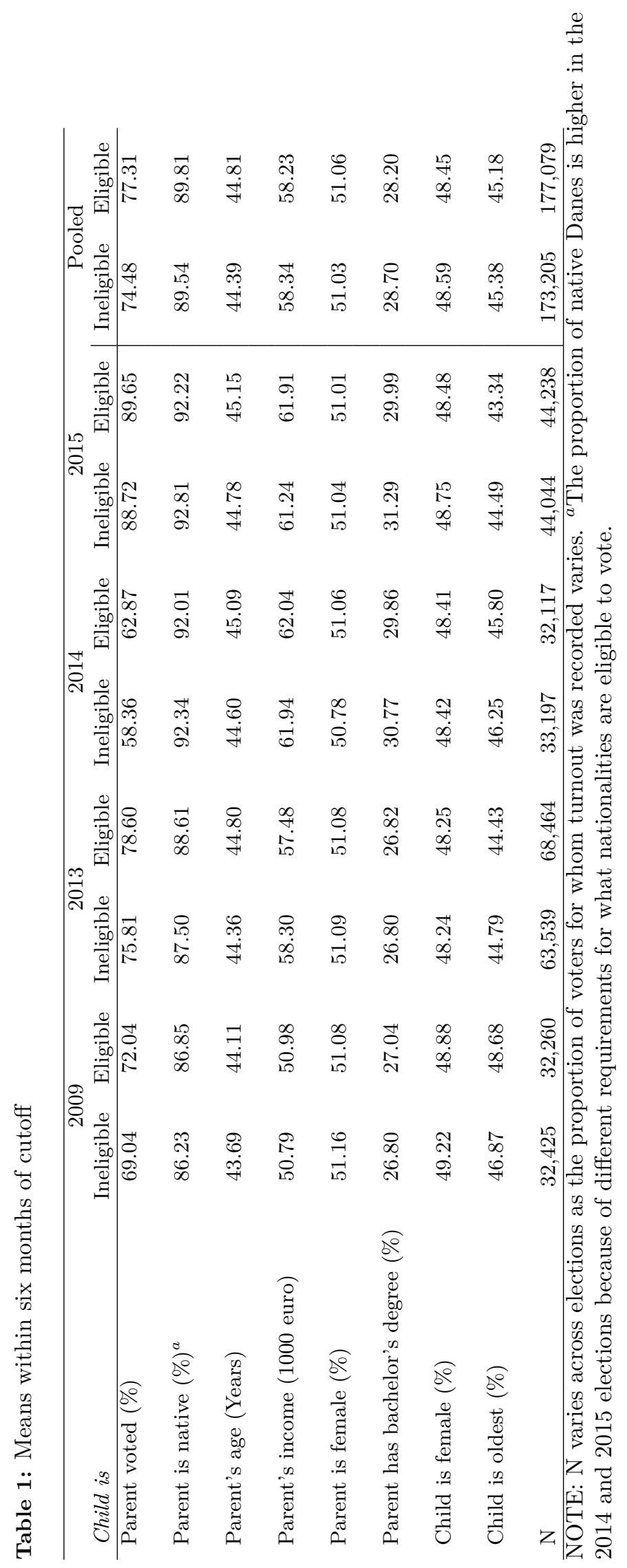




\section{Parents with eligible children are more likely to vote}

Before I estimate the effect in the cutoff, I report the means for parental turnout, whether the parent is a native Dane ${ }^{2}$, the parent's age in years, income, sex, and education, as well as the sex of the child and if the child close to the cutoff is the parent's first-born, in Table 1. The means are displayed for each year and pooled together. In all four elections, the parents of eligible voters are more likely to vote than parents of ineligible voters. In support of the assumption of no exact sorting, there are no large imbalances in covariates between the groups. I show in the supporting information that there are no effects on any of the pretreatment variables when I substitute parents' turnout with them, and that the p-values for differences in proportions is above 0.05 in a window of up to ten days.

Figure 1 shows mean turnout aggregated by day with model fits from the rdrobust-software for each election to illustrate the jumps in turnout rates around the threshold. In the left panel, I plot aggregated turnout within the bandwidths picked by the software. In the right panel, I show daily aggregates in a window of 10 days around the cutoff. The jump at the cutoff in all graphs indicates that there is a sharp increase in turnout as one's child moves from ineligibility to eligibility. Based on the figure, a linear fit within the bandwidths seems appropriate. ${ }^{3}$

In Table 2, I summarize the jumps from Figure 1. The top half shows results for all of the municipalities that I have data for in each year. There are positive effects of $3.83,1.54,4.80$, and 2.95 percentage points in the 2009, 2013, 2014, and 2015 elections respectively when we look at the conventional estimates and standard errors. In each election, baseline turnout is the average turnout for parents with ineligible children. For three of the elections, the confidence intervals are bounded well away from zero. In 2013, the point estimate is also positive, but zero is included in the confidence interval. The precision weighted estimate is 2.80 percentage points, with a standard error of 0.58 (95 percent CI $[1.66,3.94])$. Given that an average of approximately 25 percent abstain in the baseline condition, the effect corresponds to about one in nine parents being mobilized to vote.

For complicity, I also show the bias corrected estimates that the rdrobust-software returns in Table 2. They all vary within sampling variability. In the table, I also show the estimation windows picked by the algorithm, one bandwidth for estimating the regression function on both sides of the cutoff, and one for estimating the bias of the regression function. I use the default option of picking the same bandwidth on

${ }^{2}$ I follow the definition from Statistics Denmark.

${ }^{3}$ In the supporting information, I show that the results are not affected by choosing higher order polynomials. 
Figure 1: Turnout over child's age in days

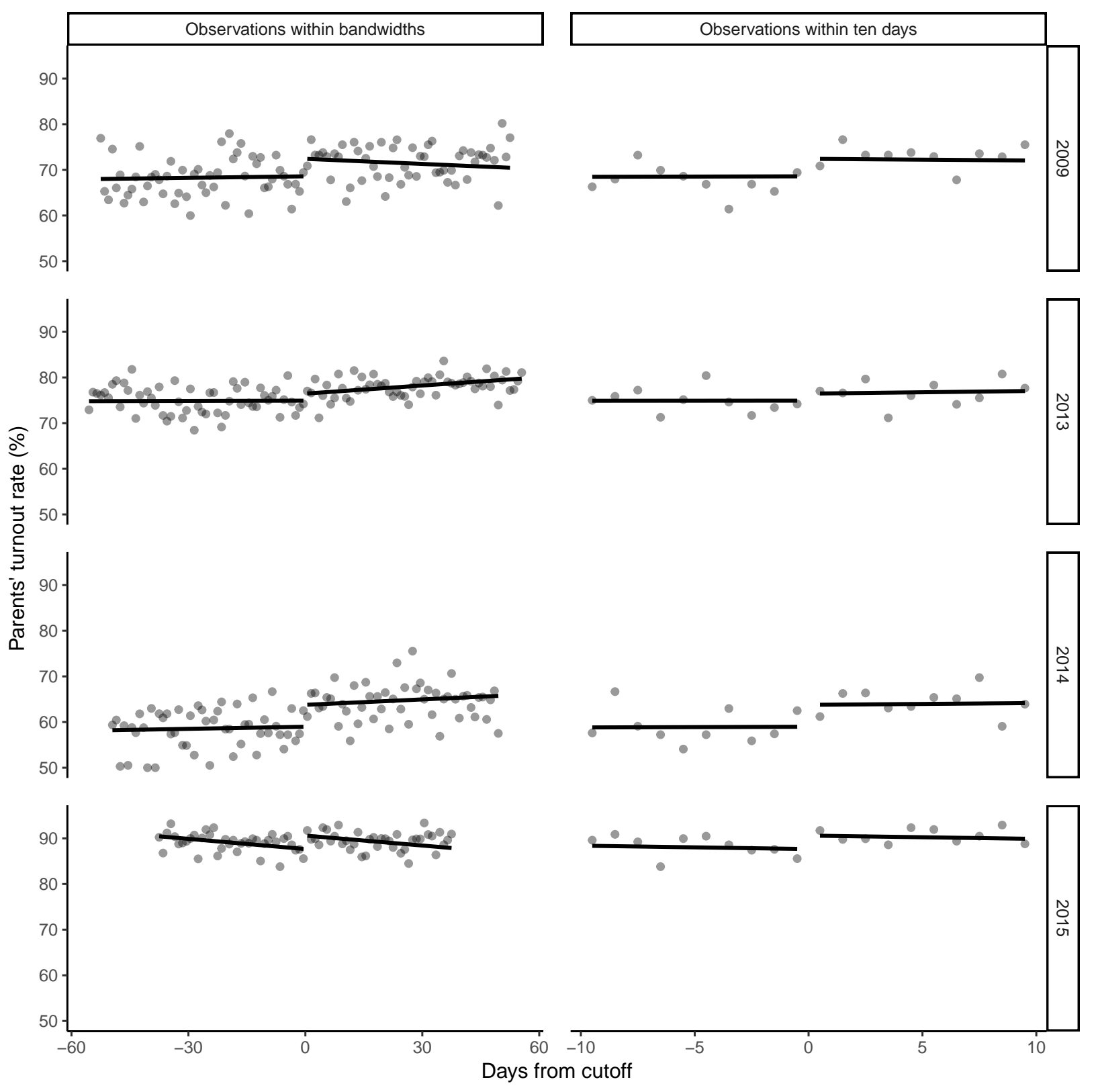

either side of the cutoff (Calonico et al. 2017). Finally, I separately report the number of included cases within the window for estimating the regression function above and below the cutoff.

In the lower half of Table 2, I show estimates for only the 32 municipalities that reported turnout in every election. Within this set of municipalities the effects are comparable across elections, although they could still differ from the effects we would observe if we had full population data. However, the estimates in the lower half of Table 2 are all well within sampling variability of the estimates in the upper half. The point estimates of the precision weighted averages are 0.09 percentage points apart. 
Table 2: Effect on turnout of parenting an eligible voter

All municipalities with data in each election

\begin{tabular}{|c|c|c|c|c|c|}
\hline & 2009 & 2013 & 2014 & 2015 & $\begin{array}{c}\text { Precision } \\
\text { weighted } \\
\text { average }\end{array}$ \\
\hline Estimate & 3.83 & 1.54 & 4.80 & 2.95 & 2.80 \\
\hline St.err. & $(1.54)$ & $(0.95)$ & $(1.60)$ & $(0.97)$ & $(0.58)$ \\
\hline $\mathrm{CI}$ & {$[0.82,6.84]$} & {$[-0.33,3.41]$} & {$[1.67,7.93]$} & {$[1.04,4.86]$} & {$[1.66,3.94]$} \\
\hline Robust estimate & 4.07 & 1.20 & 4.40 & 3.36 & 2.79 \\
\hline Robust st.err. & 1.84 & 1.10 & 1.89 & 1.09 & 0.67 \\
\hline Robust CI & {$[0.46,7.67]$} & {$[-0.95,3.35]$} & {$[0.7,8.1]$} & {$[1.22,5.50]$} & {$[1.48,4.09]$} \\
\hline Turnout $_{\text {parents of ineligible }}$ & 68.22 & 75.14 & 58.40 & 88.99 & 73.45 \\
\hline $\mathrm{N}_{\text {ineligible }}$ & 8,668 & 18,513 & 9,264 & 9,883 & 46,330 \\
\hline $\mathrm{N}_{\text {eligible }}$ & 8,659 & 19,902 & 8,963 & 9,517 & 47,043 \\
\hline Bandwidth & 53 & 56 & 50 & 38 & \\
\hline Bandwidth $_{\text {Bias-correction }}$ & 81 & 97 & 79 & 73 & \\
\hline
\end{tabular}

Municipalities with data in all four elections

\begin{tabular}{|c|c|c|c|c|c|}
\hline & 2009 & 2013 & 2014 & 2015 & $\begin{array}{c}\text { Precision } \\
\text { weighted } \\
\text { average }\end{array}$ \\
\hline Estimate & $\begin{array}{c}5.04 \\
(1.85)\end{array}$ & $\begin{array}{c}1.30 \\
(1.52)\end{array}$ & $\begin{array}{c}6.62 \\
(2.02)\end{array}$ & $\begin{array}{c}1.43 \\
(1.30)\end{array}$ & $\begin{array}{c}2.89 \\
(0.80)\end{array}$ \\
\hline CI & {$[1.42,8.66]$} & {$[-1.69,4.29]$} & {$[2.67,10.58]$} & {$[-1.12,3.97]$} & {$[1.32,4.45]$} \\
\hline Robust estimate & $\begin{array}{c}5.31 \\
(2.21)\end{array}$ & $\begin{array}{c}0.90 \\
(1.80)\end{array}$ & $\begin{array}{c}6.19 \\
(2.39)\end{array}$ & $\begin{array}{c}1.70 \\
(1.55)\end{array}$ & $\begin{array}{c}2.85 \\
(0.95)\end{array}$ \\
\hline Robust CI & {$[0.98,9.64]$} & {$[-2.62,4.43]$} & {$[1.50,10.88]$} & {$[-1.35,4.74]$} & {$[0.99,4.72]$} \\
\hline Turnout $_{\text {parents of ineligible }}$ & 67.40 & 73.19 & 57.65 & 88.54 & 71.94 \\
\hline $\mathrm{N}_{\text {ineligible }}$ & 6,009 & 7,867 & 5,766 & 6,020 & 25,662 \\
\hline $\mathrm{N}_{\text {eligible }}$ & 6,077 & 8,223 & 5,484 & 5,753 & 25,537 \\
\hline Bandwidth & 51 & 60 & 53 & 48 & \\
\hline Bandwidth $_{\text {Bias-correction }}$ & 78 & 97 & 83 & 74 & \\
\hline
\end{tabular}

\section{The effect conditional on cohabitation and level of turnout}

In Figure 2, I display yearly estimates and their precision weighted average of the effect conditional on cohabitation between the parents and children in each year. For every year, we see that parents become more likely to vote when they live with their child, while the estimate fluctuates around zero for parents who do not. The precision weighted average for parents who live with their child is around four percentage points, while the point estimate for parents who do not live with their child is negative.

Caution is warranted when interpreting treatment by covariate interactions, as the covariate, in our case cohabitation, is not randomly assigned (Gerber and Green 2012,301). One interpretation is that cohabitation 
is a necessary condition for the effect. In Denmark, one's polling place is determined based on one's address. ${ }^{4}$ Therefore, parents and children who do not live together will most often not be able to accompany each other to the polling place or even meet at the polling place. If parents vote because they want to convey the voting norm in their child, they should only do so if they can do it with their child. Likewise, if parents are mobilized to vote by their children, they may have an easier time shirking voting when they do not live together.

Figure 2: Heterogeneous effects conditional on cohabitation and level of turnout

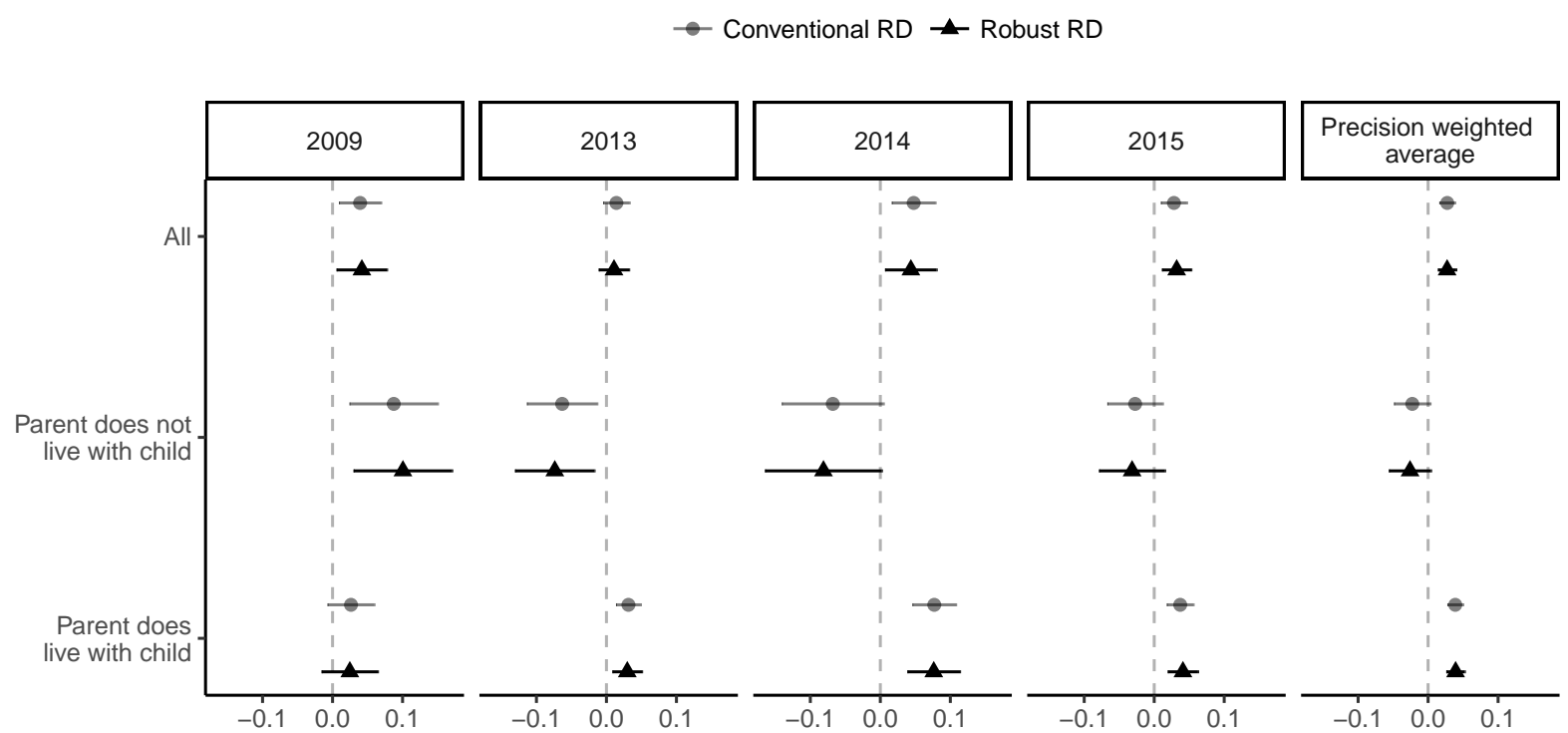

The model used to estimate the heterogeneous effects differs from the model in the main analysis in that it uses data aggregated by two days. The results are robust to using daily estimates on data that cannot be made available for replication due to privacy restrictions.

\section{Analyzing the data as a local randomized experiment}

Cattaneo, Frandsen and Titiunik (2015) propose an alternative interpretation of the RD design, in which the main assumption is that cases close to the cutoff are as-if randomly distributed and can be compared using a difference-in-proportions estimator. In Table 3, I show the pooled effect estimates across all four elections using data from all municipalities with available data for each year. I compare the proportion of

${ }^{4}$ One exception is that voters are free to vote early on any early voting location in any municipality. However, in the elections I study, only between three and eight percent of the voters voted early (Bhatti et al. 2016). 
voters that participated above and below the cutoff in windows of one day, two days, three days, one week, and one month. Table 3 shows that the results are robust to analyzing the data as a local randomized experiment. The point estimate is large and positive even in the one day window. If anything, the results suggest that we get larger effect estimates when we analyze the results as local randomized experiments and that we may underestimate the effect when we include observations outside the one week window. ${ }^{5}$ In the supporting information, I show that pretreatment covariates and the distribution of parents around the cutoff is balanced at least up to the one week window.

Table 3: Difference in the proportion of voters over bandwidth in days (averaged over all elections)

\begin{tabular}{|c|c|c|c|c|c|}
\hline Bandwidth & 1 day & 2 days & 3 days & 1 week & 1 month \\
\hline Effect on turnout & 3.21 & 4.09 & 4.80 & 3.67 & 2.66 \\
\hline $95 \% \mathrm{CI}$ & {$[-0.60 ; 7.02]$} & {$[1.37 ; 6.81]$} & {$[2.58 ; 7.02]$} & {$[2.22 ; 5.12]$} & {$[1.96 ; 3.36]$} \\
\hline Turnout $_{\text {parent of ineligible }}$ & 74.77 & 74.09 & 73.32 & 73.62 & 74.54 \\
\hline $\mathrm{N}_{\text {parent of ineligible }}$ & 979 & 1,922 & 2,882 & 6,707 & 28,813 \\
\hline $\mathrm{N}_{\text {parent of eligible }}$ & 931 & 1,847 & 2,848 & 6,724 & 28,204 \\
\hline
\end{tabular}

The table includes data from all election years (2009, 2013, 2014, and 2015). For every year all municipalities with available turnout in the given year are included.

\section{Additional robustness of the RD design}

In the supporting information, I estimate the effect in all other bandwidths both assuming the continuity of potential outcomes and analyzing it as a local randomized experiment. I also show that if I estimate the effect in mock cutoffs we never see discontinuities that compare with what we see in the true cutoff. Furthermore, I run the model using everything from a second to a sixth order polynomial for the forcing variable and run the analyses with individual level data clustered by child. I also estimate a range of placebo tests in which I switch the dependent variable with six different variables, all of which show no discontinuity in the cutoff or difference in proportions when treated as a local randomized experiment.

\section{Discussion}

I have provided causal support for the proposition that children causally affect their parents' political participation (Simon and Merrill 1998, McDevitt and Chaffee 2000, 2002, Linimon and Joslyn 2002, McDevitt and Kiousis 2006, Wong and Tseng 2008). With rich data and a strong identification strategy, I show that

\footnotetext{
${ }^{5}$ The results are robust to running the model clustered by the child on individual level data that cannot be made available for replication (not reported).
} 
when Danish children come of age, their parents' turnout rate increases, and one out of nine who would have abstained are mobilized.

Why do parents become mobilized to vote? They could hold a norm of political participation and try to pass it on to their recently enfranchised children. Alternatively, a child's engagement in the election somehow causes parents to adjust their behavior. In the supporting information, I discuss how heterogeneous effects additional to those presented above can cast light on either mechanism. First, I find an effect among both parents with a history of abstention and parents with a history of voting. I interpret this as support of both mechanisms: parents who have previously voted are more likely to repeat this behavior in order to convey that as a norm, and parents who have previously abstained become mobilized by their engaged children.

Furthermore, I look at whether the child is in high school and if the parent has completed high school. ${ }^{6}$ I find that when the child is in high school, only parents who themselves do not have a high school education are mobilized. Among the young voters, high schoolers arguably receive the most external stimuli through events in school and their friends network. In other words, they should be the most keen on voting. When the child is not in high school, the effects are similar for parents regardless of whether they have a high school diploma. For parents with a high school diploma, the effect is slightly larger when the child is in high school than when the child is not; for parents without a high school diploma, the effect is slightly smaller.

As above, we should be cautious when we interpret treatment by covariate interactions. One reading of the results is that parents who are more likely to hold a norm of voting (those who have been in high school) step up when the child lacks external stimuli (is not in high school). At the same time, parents are mobilized the most when they are least likely to hold the norm of voting (they do not have a high school diploma) and their children are most likely to vote (they are in high school). ${ }^{7}$ In other words, we can interpret the results as supporting both mechanisms.

In many countries, including Denmark, there is an ongoing debate as to whether the voting age should be lowered to 16 or 17 years, and some countries have already done this in either some or all elections (Zeglovits and Zandonella 2013, Bergh 2013, Larsen, Levinsen and Kjaer 2016). One prominent argument for lowering the voting age is that it will ensure that more young voters enter the electorate while they still live at home, in which case their parents can introduce them to voting (Franklin 2004). As I found strong evidence that

\footnotetext{
${ }^{6}$ The Danish equivalent of high school is the 'Gymnasium', which only $38.4 \%$ of the parents in the sample had completed.

${ }^{7}$ In the supporting information, I explore additional heterogeneous effects. The effect tends to be stronger for both fathers and mothers when the child coming of age is a daughter and when the parents have at least a bachelor's degree.
} 
parents are only mobilized when they live with their children, the results indicate that one advantage of a lower voting age would be that parents could become mobilized. 


\section{References}

Bergh, Johannes. 2013. "Does voting rights affect the political maturity of 16-and 17-year-olds? Findings from the 2011 Norwegian voting-age trial." Electoral Studies 32(1):90-100.

Bhatti, Yosef, Jens Olav Dahlgaard, Jonas Hedegaard Hansen, Kasper Møller Hansen and Mariann Malchau Olsen. 2016. "Fra valgstedet til indkøbscenteret: Danskernes stigende brug af brevstemmer." Politik 19(2).

Bhatti, Yosef, Kasper M Hansen and Hanna Wass. 2016. "First-time boost beats experience: The effect of past eligibility on turnout." Electoral Studies 41:151-158.

Calonico, Sebastian, Matias D Cattaneo, Max H Farrell and Rocı Titiunik. 2017. "rdrobust: Software for Regression Discontinuity Designs." The Stata Journal 17(2):372-404.

Cattaneo, Matias D, Brigham R Frandsen and Rocio Titiunik. 2015. "Randomization inference in the regression discontinuity design: An application to party advantages in the US Senate." Journal of Causal Inference 3(1):1-24.

Cattaneo, Matias D, Rocio Titiunik and Gonzalo Vazquez-Bare. 2016. "Comparing inference approaches for rd designs: A reexamination of the effect of head start on child mortality." Journal of Policy Analysis and Management, University of Michigan .

Cho, Wendy K Tam and Thomas J Rudolph. 2008. "Emanating political participation: untangling the spatial structure behind participation." British Journal of Political Science 38(02):273-289.

Coppock, Alexander and Donald P Green. 2015. "Is Voting Habit Forming? New Evidence from Experiments and Regression Discontinuities." American Journal of Political Science .

Dinas, Elias. 2014. "Does choice bring loyalty? Electoral participation and the development of party identification." American Journal of Political Science 58(2):449-465.

Franklin, Mark N. 2004. Voter turnout and the dynamics of electoral competition in established democracies since 1945. Cambridge University Press.

Gerber, Alan S and Donald P Green. 2012. Field experiments: Design, analysis, and interpretation. WW Norton.

Gidengil, Elisabeth, Hanna Wass and Maria Valaste. 2016. "Political Socialization and Voting: The ParentChild Link in Turnout." Political Research Quarterly 69(2):373-383. 
Glynn, Adam N and Maya Sen. 2015. "Identifying Judicial Empathy: Does Having Daughters Cause Judges to Rule for Women's Issues?" American Journal of Political Science 59(1):37-54.

Hahn, Jinyong, Petra Todd and Wilbert Van der Klaauw. 2001. "Identification and estimation of treatment effects with a regression-discontinuity design." Econometrica 69(1):201-209.

Holbein, John B and D Sunshine Hillygus. 2016. "Making Young Voters: The Impact of Preregistration on Youth Turnout." American Journal of Political Science 60(2):364-382.

Hyman, Herbert. 1959. Political socialization. The Free Press.

Imbens, Guido W and Thomas Lemieux. 2008. "Regression discontinuity designs: A guide to practice." Journal of econometrics 142(2):615-635.

Jennings, M Kent, Laura Stoker and Jake Bowers. 2009. "Politics across generations: Family transmission reexamined." The Journal of Politics 71(03):782-799.

Jennings, M Kent and Richard G Niemi. 1968. "The transmission of political values from parent to child." The American Political Science Review 62(1):169-184.

Jennings, M Kent and Richard G Niemi. 1981. Generations and politics: A panel study of young adults and their parents. Princeton University Press.

Larsen, Erik Gahner, Klaus Levinsen and Ulrik Kjaer. 2016. "Democracy for the youth? The impact of mock elections on voting age attitudes." Journal of Elections, Public Opinion and Parties 26(4):435-451.

Lee, David S and David Card. 2008. "Regression discontinuity inference with specification error." Journal of Econometrics 142(2):655-674.

Lee, David S and Thomas Lemieuxa. 2010. "Regression discontinuity designs in economics." Journal of economic literature 48(2):281-355.

Linimon, Amy and Mark R Joslyn. 2002. "Trickle up political socialization: The impact of kids voting USA on voter turnout in Kansas." State Politics 83 Policy Quarterly 2(1):24-36.

McDevitt, Michael and Spiro Kiousis. 2006. "Experiments in political socialization: Kids Voting USA as a model for civic education reform." The Center for Information and Research on Civic Learning and Engagement, Working Paper 49:12.

McDevitt, Michael and Steven Chaffee. 2000. "Closing gaps in political communication and knowledge effects of a school intervention." Communication research 27(3):259-292. 
McDevitt, Michael and Steven Chaffee. 2002. "From top-down to trickle-up influence: Revisiting assumptions about the family in political socialization." Political Communication 19(3):281-301.

Meredith, Marc. 2009. "Persistence in political participation." Quarterly Journal of Political Science $4(3): 187-209$.

Nyhan, Brendan, Christopher Skovron and Rocío Titiunik. 2017. "Differential Registration Bias in Voter File Data: A Sensitivity Analysis Approach.” American Journal of Political Science.

Plutzer, Eric. 2002. "Becoming a habitual voter: Inertia, resources, and growth in young adulthood." American Political Science Review 96(1):41-56.

Sears, David O and Carolyn L Funk. 1999. "Evidence of the long-term persistence of adults' political predispositions." The Journal of Politics 61(01):1-28.

Simon, James and Bruce D Merrill. 1998. "Political socialization in the classroom revisited: The Kids Voting program." The Social Science Journal 35(1):29-42.

Tedin, Kent L. 1974. "The influence of parents on the political attitudes of adolescents." American Political Science Review 68(04):1579-1592.

Urbatsch, Robert. 2014. Families' Values: How Parents, Siblings, and Children Affect Political Attitudes. Oxford University Press.

Washington, Ebonya L. 2008. "Female Socialization: How Daughters Affect Their Legislator Fathers' Voting on Women's Issues." The American economic review 98(1):311-332.

Wong, Janelle and Vivian Tseng. 2008. "Political socialisation in immigrant families: Challenging top-down parental socialisation models." Journal of Ethnic and Migration Studies 34(1):151-168.

Zeglovits, Eva and Martina Zandonella. 2013. "Political interest of adolescents before and after lowering the voting age: the case of Austria." Journal of Youth Studies 16(8):1084-1104. 